Research Article

\title{
The Cutaneous Leishmaniasis and the Sand Fly: Knowledge and Beliefs of the Population in Central Morocco (El Hajeb)
}

\author{
Karima El-Mouhdi ${ }^{D},{ }^{1}$ Abdelkader Chahlaoui, ${ }^{2}$ and Mohammed Fekhaoui ${ }^{1}$ \\ ${ }^{1}$ Geobiodiversity and Natural Patrimony (GEOPAC), Scientific Institute, Mohammed V University, Rabat, Morocco \\ ${ }^{2}$ Natural Resources Management and Development Team, Laboratory of Health and Environment, Faculty of Sciences, \\ Moulay Ismail University, Meknes, Morocco \\ Correspondence should be addressed to Karima El-Mouhdi; karima_elmouhdi@um5.ac.ma
}

Received 28 April 2020; Revised 3 November 2020; Accepted 10 November 2020; Published 18 November 2020

Academic Editor: Markus Stucker

Copyright (C) 2020 Karima El-Mouhdi et al. This is an open access article distributed under the Creative Commons Attribution License, which permits unrestricted use, distribution, and reproduction in any medium, provided the original work is properly cited.

\begin{abstract}
Background. Cutaneous leishmaniasis is a neglected parasitic dermal disease transmitted to humans through the bite of an infected female sand fly. Morocco hopes to eliminate all forms of leishmaniasis by 2030. These dermatoses pose a real public health problem in the country. Although the information is available on the disease, individual knowledge of cutaneous leishmaniasis and sand fly is not yet developed. Exploring people's beliefs and popular behaviours about cutaneous leishmaniasis and its vector allows health officials to know the sociocultural aspects of the disease and to improve prevention and control actions. Objectives. To identify the knowledge of cutaneous leishmaniasis and its vector in the population in central Morocco. Methods. Based on the epidemiological data of leishmaniases in the province of El Hajeb, we conducted a field survey and personal interviews in April and May 2019, among 281 persons belonging to the localities where leishmaniases were registered. Results. Our results show that the participants use the concept of "Chniwla" (61.6\%) for sand fly and the concept of "Hboub Chniwla" (50.8\%) for cutaneous leishmaniasis; $24.6 \%$ of the respondents do not know how the disease is transmitted to humans and $43.7 \%$ use traditional treatments and home remedies to cure themselves. $44 \%$ of participants believe that sand fly does not transmit the disease to humans and only $6.4 \%$ were aware of their responsibility in vector control. Conclusions. The study concluded that there is a need to simplify the scientific terminology in the health education of citizens regarding these dermatoses and their vector by integrating the popular concepts obtained in this study to raise public awareness and facilitate their involvement as active actors in the prevention of cutaneous leishmaniasis.
\end{abstract}

\section{Introduction}

Cutaneous leishmaniasis (CL) is a neglected dermal disease caused by Leishmania parasites transmitted to humans through the bite of an infected female sand fly [1]. Morocco is considered by the World Health Organization (WHO) as a country with a high burden of CL with an incidence rate of $5.62 \%$ and a population at risk of $14 \%$ [2]. Epidemiological data from the Moroccan Ministry of Health show that the vast majority of leishmaniasis cases are of the cutaneous type (97\%) while the rest are of the visceral type (3\%) [3]. The number of new cases of leishmaniasis registered at the national level has increased with a predominance of cutaneous leishmaniasis due to Leishmania major (L. major) (54\%), with rodents as the reservoir and Leishmania tropica (L. tropica) (43\%) with the man as a reservoir, and finally, visceral leishmaniasis due to Leishmania infantum (L. infantum) and the dog is its reservoir [3].

Geographically, the presence of CL in the different regions of the country is conditioned by the circulation of the Leishmania species in question. Therefore, the circulating species identified in the north is L. infantum; in the centre, it was $L$. tropica, while in the south the two species of $L$. major and L. tropica are responsible for the cases of cutaneous leishmaniasis [4]. Transmission is mainly anthroponotic in cases of L. tropica and zoonotic in cases of L. infantum and L. major [5-9]. 
Even though the fight against this dermatosis was officially launched in 1997 by the implementation of a national programme to control leishmaniases [10], the health authorities announced that the epidemiological situation of CL is still worrying and that their elimination must be maintained by 2030 to align with the health objectives of the 2030 sustainable development agenda in which Morocco was included [3].

At present, most of the work that was done on CL in Morocco focuses on the eco-epidemiological and parasitological aspects of the disease [7, 9, 11-13]. However, no studies were made to describe the sociocultural aspects of the disease. It is within this framework that the present study was conducted, for the first time notably in the centre of the country in the province of El Hajeb, to explore the beliefs and popular behaviours of individuals concerning cutaneous leishmaniasis and its vector.

The control and prevention of cases of CL attributed to L. tropica, whose disease reservoir is human, consists mainly of health education of the population at risk to protect themselves against the risk of sand fly bites and to consult in the event of the appearance of skin lesions in order to minimise and limit the circulation of the parasite between individuals. In central Morocco, where CL due to L. tropica circulates [10], the importance of awareness and education of people is essential to control and limit the spread of these dermatoses in these areas. Therefore, people suffering from CL should be encouraged to seek care from health professionals [14]. However, the perception of the disease and its treatment greatly influences how people use health services $[14,15]$. The success of programmes for the prevention and control of any human disease depends on the active participation of the community. The involvement of the affected population is important to achieve the elimination goals of the leishmaniasis control programme. The programme must understand the popular beliefs and behaviours of individuals regarding CL and its vector as they are crucial determinants of community involvement. The results of this study can help health officials to improve the implementation of $\mathrm{CL}$ control activities in central Morocco. Moreover, the results obtained can be used to propose a regional plan adapted to the sociocultural context and appropriate to accelerate the process of CL elimination, especially in the central regions of the country.

The aim of this work is to explore beliefs and identify popular concepts surrounding the disease and its vector to understand the care-seeking behaviours of the population. The specific factors sought are knowledge of cutaneous leishmaniasis disease, attitudes and behaviours related to the treatment of skin lesions, mode of transmission, sand fly, and preventive measures. The objective of this study is to shed new light on the problem of cutaneous leishmaniasis by examining the beliefs and behaviours of individuals seeking care. Therefore, the results obtained can be applied to the prevention and control of CL insofar as they allow program decision-makers to initiate control activities adapted to the sociocultural context of the affected population in the central regions of Morocco and any other similar region.

\section{Materials and Methods}

2.1. Study Area. The study was conducted in the province $\left(33^{\circ} 41^{\prime} \mathrm{N}, 5^{\circ} 22^{\prime} \mathrm{W}\right)$ located in central Morocco, at an altitude of $1000 \mathrm{~m}$ and a temperate climate. Annual rainfall varies between $400 \mathrm{~mm}$ and $600 \mathrm{~mm}$ [16]. It is bordered to the east by the province of Séfrou, to the west by the province of Khémissate, to the north by the prefecture of Meknes, and to the south by the province of Ifrane. It is a predominantly rural province with scattered groups of extended families attached to their farmland. With a population of 247,016 inhabitants and a surface area of $2193.41 \mathrm{~km}^{2}$, the province is organised into 16 communes, of which 12 are rural [17]. Economically and agroindustrially, the province of El Hajeb is celebrated nationally for its onion production (62\% of national production), it is an important area for the central region of the country and offers employment opportunities throughout the year, and it is a meeting place for seasonal workers to participate in the cultivation and harvesting of onions (62\% of national production) [18]. These workers come in particular from neighbouring provinces such as Fez, Séfrou, and Moulay Yacoub, which have recently declared as endemic foci of cutaneous leishmaniasis in central Morocco [13, 19, 20].

\subsection{Epidemiological Data and Justification of the Study.} Epidemiological data on human cases of leishmaniases were obtained from the health authorities at the delegation of the Ministry of Health at the level of El Hajeb province. Between 2013 and 2017, 21 new cases of leishmaniases were reported and were the subject of an epidemiological study [12]. The said study revealed the coexistence of the two forms of leishmaniasis with a predominance of the cutaneous form ( $81 \%$ ) of the cases compared to $19 \%$ of the cases with visceral leishmaniasis. The first age of the disease infestation among the autochthonous cases was 13 months for LV and 24 months for CL. The majority of the reported cases are indigenous cases from rural areas (75\%) of the new cases. $62 \%$ of these cases are notified in the communes of Bitit and Laqsir, which are located near the commune of Ain Chgag (province of Séfrou) [12]. The said study concluded that the displacement of people seeking seasonal employment, the increase of exchange with neighbouring provinces that are declared highly affected by CL, and the existence of ecological and environmental conditions favourable to the multiplication of disease-carrying insects and the proliferation of rodents increase the risk of the spread of CL disease in the population of El Hajeb, and education sessions will be necessary to prevent such a situation. But awareness about a disease first requires health professionals to have an idea about the population's knowledge and beliefs about the disease to correct misconceptions and improve true knowledge. Providing health actors with information on the level of knowledge of the population about the CL disease is therefore the ultimate goal of this study.

2.3. Study Design and Sampling. The study was based on the epidemiological data of leishmaniases in the province of El Hajeb to conduct an exploratory survey on the knowledge 
of CL by the population in the communes that were affected by this disease in recent years [12]. Therefore, the communes that were selected are Laqsir, Bitit, Ain Taoujdate, El Hajeb, Sabaa Ayoune, Bouderbala, Agourai, and Ait Oukhlifen. The survey was carried out between April and June 2019 door-to-door among 281 people in the city of El Hajeb.

The methodology followed for the design of the survey was that of Khan et al. [21], and the data collection tool was constructed following Frary's guidelines for a questionnaire [22]. The questionnaire consisted of four parts:

(a) The sociodemographic characteristics of the participants

(b) The population's knowledge of CL, its mode of transmission, and treatment attitudes

(c) Citizens' knowledge and beliefs about the sand fly and their ability to transmit diseases

(d) The measures used to avoid the disease

The information was collected using a pretested assisted questionnaire, translated into the local language, and validated with twenty-one people living in the city of Meknes and with sociodemographic characteristics similar to those of the population studied. The interviews were conducted door-to-door by nursing and health science students who were fluent in the city's two local dialects (Arabic and Berber). These students were familiar with the city and its inhabitants because of their frequent visits to the various health institutions during their work placements. Also, they are familiar with field research and how to conduct surveys scientifically and ethically, gathering the necessary information on the concepts used.

Participants were selected based on convenience sampling and their willingness to participate in the study. The criteria for inclusion were being adult, living in and originally from El Hajeb. While the exclusion criteria were refusal to participate in the survey, persons under 16 years of age, and those living in the city for less than six months.

Thus, the data obtained were entered into Excel, doublechecked, and then transferred to Epi Info 7 for processing and statistical analysis. The results were presented as percentages and tables.

2.4. Ethical Considerations. Before conducting the study, we obtained the administrative authorization from the delegation of the Ministry of Health of the city of El Hajeb to carry out this survey. Also, all participants were informed about the objectives of the study and the full respect of the confidentiality of their identities and answers. They were, therefore, free to accept or refuse to participate in the study, as recommended by experts in scientific research ethics [23]. Thus, free and informed consent was obtained orally, and the interviews were carried out with only those people who freely agreed to participate in our study and to answer our questions, and after each interview, the participant received information about cutaneous leishmaniasis, its mode of transmission, and preventive measures.

\section{Results and Discussion}

Cutaneous leishmaniasis is a real public health problem, which has obliged the Ministry of Health to implement a national programme for the control of CL since 1997 [4]. Controlling the epidemiological situation of these diseases has become a national priority, particularly to achieve the health objectives of the 2030 sustainable development agenda in which Morocco is involved.

Despite efforts to control and eliminate $\mathrm{CL}$ at the national level, Morocco still suffers from the spread of these parasitoses. Most of the work that was carried out at the national level on CL focuses on the eco-epidemiological and parasitological aspects of the disease [6-8, 11-13]. To date, no research was carried out to study the sociocultural aspects of these parasitic dermatoses. It is within this framework that the results of this study are presented to describe, for the first time in Morocco, popular beliefs and behaviours of individuals concerning $\mathrm{CL}$ and its vector to better understand care-seeking behaviours.

\subsection{The Sociodemographic Characteristics of the Participants.} Table 1 presents the sociodemographic characteristics of the participants in terms of age, sex, marital status, education, occupation, and place of residence. Analysis of the results shows that women represent $68.0 \%$ and married persons represent $74.7 \%$ of the total number of participants. The age of participants ranges from 16 to 67 years, and the age group 41-50 has the highest participation rate of $26.7 \%$. In terms of education level, the study sample revealed that $34.5 \%$ of participants have primary school education and $28.1 \%$ of participants are illiterate. In terms of the type of activity practised, housewives accounted for $27.0 \%$, followed by those working in agriculture and livestock with a percentage of $20.8 \%$.

Research results reveal that the rural population represents more than half of the participants (55.2\%). Most of the respondents belong to poor families with a fragile social level and 55.9\% have less than 3000 Moroccan dirhams per month, equivalent to US $\$ 300$ per month. Also, $53.4 \%$ of the participants are vulnerable and have benefited from the Medical Assistance Regime for the Economically Diminished (MARED) and 22.8\% have no medical coverage.

\subsection{Behaviours of Citizens towards Cutaneous Leishmaniasis} and the Use of Protective Measures. Table 2 presents the knowledge and behaviour of individuals regarding CL transmitted by sand fly. One of the most important results is that more than half of the participants have heard about CL (56.2\%). But when pictures of skin lesions due to CL were shown, people were asked, "Have you ever seen a person with these skin lesions?" It turned out that the rate rose to $69.4 \%$. Also, $50.8 \%$ said that these lesions are recognized by the popular name of "Hboub of Chniwla," $12.8 \%$ said it is "Hboub of Namos," $11.3 \%$ said it is "Hboub of Timsi/Bonif," and 9.2\% called it "Nar Lfarsiya," and 3. 6\% of them believe that these skin lesions are the result of witchcraft appearing 
TABLE 1: Sociodemographic characteristics of participants.

\begin{tabular}{|c|c|c|c|}
\hline & Variable & Number $(n=281)$ & Percentage (\%) \\
\hline \multirow{2}{*}{ Middle of life } & Urban & 126 & 44.8 \\
\hline & Rural & 155 & 55.2 \\
\hline \multirow{6}{*}{ Age group } & [16-20] & 17 & 6.0 \\
\hline & {$[21-30]$} & 61 & 21.7 \\
\hline & [31-40] & 69 & 24.6 \\
\hline & {$[41-50]$} & 75 & 26.7 \\
\hline & Over 50 years old & 54 & 19.2 \\
\hline & Unanswered & 5 & 1.8 \\
\hline \multirow{6}{*}{ Level of education } & Illiterate & 79 & 28.1 \\
\hline & Primary & 97 & 34.5 \\
\hline & College & 62 & 22.1 \\
\hline & Secondary & 23 & 8.2 \\
\hline & Superior & 17 & 6.0 \\
\hline & Unanswered & 3 & 1.1 \\
\hline \multirow{6}{*}{ Occupation } & Housewife & 76 & 27.0 \\
\hline & Public servant & 33 & 11.7 \\
\hline & Farmer/breeders & 58 & 20.8 \\
\hline & Worker & 28 & 10.0 \\
\hline & Works day labourer & 45 & 16.0 \\
\hline & Other occupations & 41 & 14.6 \\
\hline \multirow{2}{*}{ Gender } & Man & 91 & 32.0 \\
\hline & Woman & 191 & 68.0 \\
\hline \multirow{4}{*}{ Family status } & Unmarried & 46 & 16.4 \\
\hline & Married & 210 & 74.7 \\
\hline & Widower & 16 & 5.7 \\
\hline & Divorced & 9 & 3.2 \\
\hline \multirow{4}{*}{ Monthly family income } & $<300 \$$ & 157 & 55.9 \\
\hline & [300-500] & 69 & 24.6 \\
\hline & {$[500-700]$} & 38 & 13.5 \\
\hline & $>700 \$$ & 17 & 6.0 \\
\hline \multirow{4}{*}{ Health coverage } & National fund for social welfare & 23 & 8.2 \\
\hline & National social security fund & 44 & 15.7 \\
\hline & Medical assistance regime for the economically disadvantaged & 150 & 53.4 \\
\hline & None & 64 & 22.8 \\
\hline \multirow{5}{*}{ Housing type } & A traditional house made of wood, brick, and pewter & 64 & 22.8 \\
\hline & A traditional cement house & 121 & 43.1 \\
\hline & Modern Moroccan house & 71 & 25.3 \\
\hline & Apartment & 23 & 8.2 \\
\hline & Villa & 2 & 0.7 \\
\hline
\end{tabular}

on the skin of the victim "Tokal." In the Moroccan dialect, the term "Hboub" refers to a lesion that affects the skin.

And on how a person is affected, $18.1 \%$ think the disease is caused by eating contaminated food. As for $24.6 \%$ of them, they do not know how the contamination occurs, while $34.9 \%$ say the infection was due to insect bites. This finding was confirmed by Koirala et al.'s study in Nepal, where they were able to show that most participants do not have a clear idea of how the disease is transmitted to humans [24]. Another study of CL knowledge and practice in southern Iran by Sarkari et al. showed that more than half of those affected by the disease believed that CL was caused by a microbe and not the Leishmania parasite [25]. In a very recent study conducted in the Volta region of Ghana, it was found that most of the inhabitants $(88.3 \%)$ had satisfactory knowledge of CL but not of the vector and the mode of transmission [26].
Of the 98 people who confirmed that the CL lesions were caused by insect bites, $54.1 \%$ gave the name "Chniwla," and 23.5\% said it was "Namos," i.e., mosquitoes, $7.1 \%$ said it was spiders, however, $5.1 \%$ said it was sand fly, and $2.5 \%$ did not know the name of the insect. This was consistent with the results of Sarkari and colleagues where they found that $63.5 \%$ of the inhabitants thought that mosquito bites could cause the disease and not sand fly [25]. In another study in Punjab, Pakistan, Akram and colleagues found that people often confused mosquitoes with sand fly as the true vectors of CL [27].

Regarding the severity of these skin lesions, the results showed that $33.1 \%$ of the participants did not consider them to be serious at all and $31.0 \%$ considered them to be relatively serious, while $25.3 \%$ did not know how serious they were. As for the curability of these lesions, $70.1 \%$ think that they could be cured, but more than a quarter $(28.5 \%)$ did not know if 
TABle 2: Citizens' knowledge and beliefs about cutaneous leishmaniasis.

\begin{tabular}{|c|c|c|c|}
\hline Question & Answer & $\begin{array}{l}\text { Number } \\
(n=281)\end{array}$ & $\begin{array}{l}\text { Percentage } \\
(\%)\end{array}$ \\
\hline \multirow{2}{*}{ Have you heard of cutaneous leishmaniasis? } & Yes & 158 & 56.2 \\
\hline & No & 123 & 43.8 \\
\hline \multirow{3}{*}{$\begin{array}{l}\text { Have you ever had or seen anyone with such skin lesions? (picture } \\
\text { of cutaneous leishmaniasis) }\end{array}$} & Yes & 195 & 69.4 \\
\hline & No & 82 & 29.2 \\
\hline & No answer & 4 & 1.4 \\
\hline \multirow{5}{*}{ What do you call these skin lesions? } & Hboub Chniwla & 99 & 50.8 \\
\hline & Hboub Namos & 25 & 12.8 \\
\hline & Hboub timssi/Hboub Bonif & 22 & 11.3 \\
\hline & Nar Lfarsiya & 18 & 9.2 \\
\hline & Sorcery (magic) & 7 & 3.6 \\
\hline \multirow{5}{*}{ In your opinion, are these skin lesions considered? } & Very serious & 11 & 3.3 \\
\hline & Serious & 19 & 6.8 \\
\hline & Mildly severe & 87 & 31.0 \\
\hline & Never mind & 93 & 33.1 \\
\hline & I do not know & 71 & 25.3 \\
\hline \multirow{3}{*}{ In your opinion, are these skin lesions curable? } & Yes & 197 & 70.1 \\
\hline & No & 4 & 1.4 \\
\hline & I do not know & 80 & 28.5 \\
\hline \multirow{4}{*}{ If yes, how is it possible? (you can answer several choices) } & $\begin{array}{l}\text { Through treatment by a health care } \\
\text { professional }\end{array}$ & 124 & 44.1 \\
\hline & By treatment at the pharmacist's & 34 & 12.1 \\
\hline & $\begin{array}{l}\text { Use of home-prepared self-treatment } \\
\text { recipes }\end{array}$ & 65 & 23.1 \\
\hline & By remedies from the traditional healer & 58 & 20.6 \\
\hline \multirow{7}{*}{$\begin{array}{l}\text { In your avis, how can cutaneous leishmaniasis be transmitted to } \\
\text { humans? (you can answer several choices) }\end{array}$} & By insect stings & 98 & 34.9 \\
\hline & By consuming contaminated food & 51 & 18.1 \\
\hline & By the polluted water & 26 & 9.3 \\
\hline & By the polluted air & 12 & 4.3 \\
\hline & By an animal bite & 9 & 3.2 \\
\hline & Other means & 16 & 5.7 \\
\hline & I do not know & 69 & 24.6 \\
\hline \multirow{6}{*}{$\begin{array}{l}\text { If cutaneous leishmaniasis is transmitted to humans by insects, } \\
\text { what kind of insects? }\end{array}$} & Chniwla & 53 & 54.1 \\
\hline & Namos (mosquitoes) & 23 & 23.5 \\
\hline & Spiders & 7 & 7.1 \\
\hline & Sand fly & 5 & 5.1 \\
\hline & Other insects & 8 & 8.1 \\
\hline & I do not know & 2 & 2.0 \\
\hline \multirow{3}{*}{ In your opinion, is this skin disease preventable? } & Yes & 174 & 61.9 \\
\hline & No & 88 & 31.3 \\
\hline & I do not know & 19 & 6.8 \\
\hline \multirow{4}{*}{ If yes, what is the method? (you can answer several choices) } & $\begin{array}{l}\text { Avoid approaching or touching the } \\
\text { person with the disease }\end{array}$ & 62 & 22.1 \\
\hline & $\begin{array}{l}\text { Avoid infection by isolating the affected } \\
\text { person }\end{array}$ & 12 & 4.3 \\
\hline & Avoid sick animals & 16 & 5.7 \\
\hline & Avoid insect stings & 84 & 29.9 \\
\hline
\end{tabular}

they were curable or not. It was interesting to note that to treat CL, the population used traditional therapeutics (20.6\%), applied basil and vinegar-based recipes instead of the bite $(23.1 \%)$, and used substances on skin lesions such as bleach (sodium hypochlorite) and perfumes, while $44.1 \%$ reported that they were treated by health care professionals. This finding was consistent with similar studies conducted in Suriname by Ramdas who found that patients with skin lesions used hazardous chemicals to treat CL [28]. In another recent study conducted by Doe in Ghana, it was found that most people believed that CL is primarily cured by a local type of herb [26].

From the Moroccan sociocultural point of view, these results could be explained, on the one hand, by the fact that the practices of the inhabitants of the city of El Hajeb in the centre of the country for the treatment of CL lesions did not differ from the results found by Bennis and his colleagues in the provinces of "Tinghir" and "Errachidia" in the south of 
TABle 3: Citizens' views on skin lesions.

\begin{tabular}{|c|c|c|c|}
\hline Question & Answer & $\begin{array}{l}\text { Number } \\
(n=281)\end{array}$ & $\begin{array}{l}\text { Percentage } \\
(\%)\end{array}$ \\
\hline \multirow{3}{*}{$\begin{array}{l}\text { In your opinion, do dermal diseases require the advice of a health } \\
\text { professional? }\end{array}$} & Yes & 156 & 55.5 \\
\hline & No & 111 & 39.5 \\
\hline & I do not know & 14 & 5.0 \\
\hline \multirow{3}{*}{$\begin{array}{l}\text { In your opinion, can dermal diseases be a health problem for the } \\
\text { individual? }\end{array}$} & Yes & 184 & 65.7 \\
\hline & No & 92 & 32.7 \\
\hline & I do not know & 5 & 1.8 \\
\hline \multirow{15}{*}{$\begin{array}{l}\text { If so, for whom could skin disease be a health problem? And in what area } \\
\text { of the body? (you can answer with several choices) }\end{array}$} & For the man & 63 & 34.2 \\
\hline & For the married woman & 76 & 41.3 \\
\hline & For the unmarried woman & 85 & 46.2 \\
\hline & For the little girl & 182 & 98.9 \\
\hline & For the little boy & 179 & 97.3 \\
\hline & $\begin{array}{l}\text { If the skin lesion is in a visible } \\
\text { area of the body }\end{array}$ & 175 & 95.1 \\
\hline & Feet & 51 & 27.7 \\
\hline & Hands & 42 & 22.8 \\
\hline & The face & 172 & 93.5 \\
\hline & $\begin{array}{c}\text { Another skin lesion is in a } \\
\text { visible } \text { area* }^{*}\end{array}$ & 27 & 14.7 \\
\hline & $\begin{array}{l}\text { If the skin lesion is in a hidden } \\
\text { area of the body }\end{array}$ & 178 & 96.7 \\
\hline & The abdomen & 75 & 40.8 \\
\hline & The back & 50 & 27.2 \\
\hline & The genitals & 173 & 94.0 \\
\hline & $\begin{array}{c}\text { Another skin lesion is in a } \\
\text { hidden area** }\end{array}$ & 92 & 50.0 \\
\hline
\end{tabular}

${ }^{*}$ The scalp; ${ }^{* *}$ breasts.

Morocco, who also used traditional treatments and selfmedication practices [29]. On the other hand, these behaviours revealed gaps and inadequacies in the knowledge of Moroccans and their misconceptions about the effectiveness of traditional treatments despite the free and available medical treatment in health centres. This revealed the importance of implementing health awareness and education strategies.

Concerning the possibility of prevention against CL, the results obtained showed that $31.5 \%$ of the participants think that CL was not preventable and $6.8 \%$ did not know if it is possible to prevent this disease. On the other hand, $61.9 \%$ stressed the possibility of prevention. In this context, when we asked the question "How can prevention be done and what was the method?", it turned out that $29.9 \%$ thought that prevention consists in avoiding insect bites, $22.1 \%$ thought that prevention consists in avoiding contact with people with this disease, and $4.3 \%$ said that prevention consists in isolating the sick person. These findings corroborated with Abazid's study in Aleppo, Syria, who found that most residents used mosquito nets to protect themselves from bites and did not believe that the disease is contagious [30].

Cutaneous leishmaniasis, as a lesion affecting the skin, can leave permanent disfigurement and negative impacts on the psychological and social life of the affected people [29]. The benign nature of dermatosis often classifies it as a secondary rodent compared to other fatal diseases. As a result, the CL is considered by the $\mathrm{WHO}$ as a tropical disease neglected by health systems [31]. Nevertheless, this neglect can also be seen in individuals themselves. When we asked the question: "Do you think that skin lesions require the consultation of a health professional?" (Table 3 ), the results show that $32.4 \%$ of the participants answered "no" and $5.0 \%$ did not know if these skin diseases required medical consultation, while $55.5 \%$ of respondents indicated that skin diseases require the advice of a health professional.

And when we asked them: "Can skin diseases be a health problem?", it turned out that a third of the participants $(32.7 \%)$ did not consider them to be a health problem, while $65.7 \%$ responded that they could be a problem if the skin lesion was in a hidden area of the body such as the genitals (94.0\%), or when it was in an exposed area of the body such as the face (93.5\%). We also found that skin diseases are related to gender, as the majority of respondents reported that they can be a health problem for women. Similarly, skin diseases are related to childhood, as they are considered a health problem if they affect young children, regardless of gender: $97.3 \%$ for boys and $98.9 \%$ for girls. These results can be explained by the fact that the perceptions of the inhabitants of central Morocco about these skin lesions are the same as those of the inhabitants of the province of San José in Costa Rica because they only consider CL as a health problem if their children are affected [32]. Also, CL is not considered a health priority for the population in the south of the country compared to the many competing health problems [29]. 
TABLe 4: Citizens' knowledge and beliefs about the sand fly.

\begin{tabular}{|c|c|c|c|}
\hline Question & Answer & $\begin{array}{l}\text { Number } \\
(n=281)\end{array}$ & $\begin{array}{l}\text { Percentage } \\
\quad(\%)\end{array}$ \\
\hline \multirow{3}{*}{$\begin{array}{l}\text { In your opinion, is there a difference between sand fly and } \\
\text { mosquitoes? }\end{array}$} & Yes & 196 & 69.8 \\
\hline & No & 76 & 27.0 \\
\hline & I do not know & 9 & 3.2 \\
\hline \multirow{3}{*}{ What do you call sand fly? } & Chniwla & 173 & 61.6 \\
\hline & Namos & 97 & 34.5 \\
\hline & I do not know & 11 & 3.2 \\
\hline \multirow{11}{*}{ Do you know the breeding grounds of sand fly? } & Water of all kinds & 116 & 41.3 \\
\hline & Stagnant water & 32 & 11.4 \\
\hline & Polluted water & 64 & 22.8 \\
\hline & Damp places & 19 & 6.8 \\
\hline & Dry places & 3 & 1.1 \\
\hline & Cold places & 22 & 7.8 \\
\hline & Dirty and polluted places & 81 & 28.8 \\
\hline & Waste and garbage disposal places & 128 & 45.6 \\
\hline & Human excrement & 62 & 22.1 \\
\hline & Animal manure & 48 & 17.1 \\
\hline & I do not know & 47 & 16.7 \\
\hline \multirow{2}{*}{$\begin{array}{l}\text { Have you ever received information on diseases transmitted } \\
\text { by sand fly? }\end{array}$} & Yes & 99 & 35.2 \\
\hline & No & 182 & 64.8 \\
\hline \multirow{6}{*}{ If yes, from whom? } & Internet & 47 & 47.5 \\
\hline & Friend/Neighbour & 45 & 45.5 \\
\hline & Television & 39 & 39.4 \\
\hline & Health care professional & 24 & 24.2 \\
\hline & Radio & 6 & 6.1 \\
\hline & School & 2 & 2.0 \\
\hline \multirow{3}{*}{ In your opinion, can sand fly transmit diseases? } & Yes & 95 & 33.8 \\
\hline & No & 124 & 44.1 \\
\hline & I do not know & 62 & 22.1 \\
\hline \multirow{5}{*}{ If yes, to whom can diseases be transmitted? } & The human & 67 & 70.5 \\
\hline & The animal & 26 & 27.4 \\
\hline & Human and animal & 76 & 80.0 \\
\hline & Trees and plants & 4 & 4.2 \\
\hline & I do not know & 19 & 20.0 \\
\hline \multirow{10}{*}{ What are these diseases? } & Skin diseases & 87 & 91.6 \\
\hline & Allergy & 36 & 37.9 \\
\hline & Fever & 23 & 24.2 \\
\hline & Cutaneous leishmaniasis & 21 & 22.1 \\
\hline & Eye diseases & 17 & 17.9 \\
\hline & Diarrhoea & 7 & 7.4 \\
\hline & Malaria & 3 & 3.2 \\
\hline & Asthma & 2 & 2.1 \\
\hline & Influenza & 2 & 2.1 \\
\hline & $\begin{array}{c}\text { Yes, but I do not know the name of the } \\
\text { disease }\end{array}$ & 7 & 8.4 \\
\hline
\end{tabular}

3.3. Citizens' Knowledge and Beliefs about Sand Fly. Table 4 presents the results of research on citizens' knowledge and beliefs about a sand fly, where they live and reproduce, and their ability to transmit diseases. Among the important results obtained, the majority of participants know sand fly under the name "Chniwla" (61.6\%) and the name "Namos" (34.5\%). And when we asked them: "Is there a difference between sand fly and mosquitoes?", it turned out that $69.8 \%$ of the participants thought there was no difference and $3.2 \%$ said they did not know. These results confirm those reached by Bennis and his colleagues when they carried out their qualitative research on the psychological effects of CL in south-eastern Morocco in the regions of Tinghir and Errachidia, where it was discovered that the victims of CL use the names "Chniwla" and "Namos" to designate the insect that bit them and caused the skin scars [29]. Therefore, it can be said that the local name of sand fly in Morocco does not differentiate between its interior and southern regions [14]. Also, the lack of distinction between mosquitoes and sand fly was not only observed among Moroccans but was also raised among residents of Punjab, Pakistan, where participants were unable to distinguish between these two small insects [27]. In Sri Lanka and Ecuador, the degree of mixing was important because no distinction was made between sand fly and mosquitoes and they were used as synonyms $[24,33]$. 
TABLE 5: Measures used by citizens to protect themselves against insect bites.

\begin{tabular}{|c|c|c|c|}
\hline Question & Answer & $\begin{array}{l}\text { Number } \\
(n=281)\end{array}$ & $\begin{array}{l}\text { Percentage } \\
(\%)\end{array}$ \\
\hline \multirow{8}{*}{$\begin{array}{l}\text { In your opinion, the control of disease-carrying insects is a responsibility } \\
\text { of (you can answer with several choices) }\end{array}$} & The Ministry of Health & 73 & 26.0 \\
\hline & The Ministry of Agriculture & 52 & 18.5 \\
\hline & $\begin{array}{l}\text { Ministry of the Interior } \\
\text { (municipality) }\end{array}$ & 30 & 10.7 \\
\hline & The three departments & 24 & 8.4 \\
\hline & The person himself & 18 & 6.4 \\
\hline & Associations and NGOs & 10 & 3.6 \\
\hline & $\begin{array}{l}\text { Shared responsibility among } \\
\text { stakeholders }\end{array}$ & 60 & 21.4 \\
\hline & I do not know & 8 & 2.8 \\
\hline \multirow{3}{*}{ In your opinion, can sand fly be avoided? } & Yes & 120 & 42.7 \\
\hline & No & 148 & 52.7 \\
\hline & I do not know & 13 & 4.6 \\
\hline \multirow{6}{*}{ If yes, how is that possible? (you can answer with several choices) } & Basil & 109 & 90.8 \\
\hline & Vinegar & 72 & 60.0 \\
\hline & Pesticide (powder) & 67 & 55.8 \\
\hline & Lemon & 55 & 45.8 \\
\hline & Mint & 19 & 15.8 \\
\hline & Cleanliness & 24 & 20.0 \\
\hline \multirow{12}{*}{$\begin{array}{l}\text { To protect yourself from insect bites, use yourself (you can answer with } \\
\text { several choices) }\end{array}$} & Pesticide pump & 196 & 69.8 \\
\hline & Plants & 147 & 52.3 \\
\hline & Curtains in the windows & 131 & 46.6 \\
\hline & Wear long-sleeved shirts & 70 & 24.9 \\
\hline & Curtains at the doors & 65 & 23.1 \\
\hline & Wearing pants & 57 & 20.3 \\
\hline & $\begin{array}{l}\text { Electrical distributors for } \\
\text { pesticides }\end{array}$ & 50 & 17.8 \\
\hline & Screens in doors and windows & 48 & 17.1 \\
\hline & Fan (air conditioner) & 36 & 12.8 \\
\hline & $\begin{array}{l}\text { Insecticide-impregnated } \\
\text { mosquito nets }\end{array}$ & 25 & 8.9 \\
\hline & Mosquito nets around the bed & 5 & 1.8 \\
\hline & Other means & 38 & 13.5 \\
\hline
\end{tabular}

About the knowledge of the place of reproduction and proliferation of sand fly, several studies revealed the erroneous knowledge of individuals $[34,35]$. This was confirmed in our resultants since $41.3 \%$ of the participants believe that sand fly develops in water, especially polluted water $(22.8 \%)$ or waste and garbage disposal places (45.6\%). But only $17.1 \%$ said that the manure of the animals is the place of reproduction of these insects and $16.7 \%$ of the respondents did not know where they reproduce.

Knowledge of individuals at risk of disease transmission by sand fly is an essential factor in ensuring primary prevention of CL. Our results show that $44.1 \%$ of respondents believe that sand fly is incapable of transmitting diseases, $22.1 \%$ do not know if it is capable of doing so, while only $33.8 \%$ of respondents indicated that these insects can transmit diseases. And for those who have already recognized the pathogenic capacity of the sand fly, $80.0 \%$ of them say that it transmits diseases to humans and animals, while $4.2 \%$ think that it transmits diseases to trees and plants.

According to participants, sand fly-borne diseases include skin diseases (91.6\%), allergic diseases (37.9\%), fever (24.2\%), skin leishmaniasis (22.1\%), and eye diseases
(17.9\%). In a similar study conducted in Pakistan by Akaram and colleagues with 250 people, they concluded that only a few participants (9.2\%) thought that sand fly transmitted CL and the others thought that it transmitted fever, diarrhoea, respiratory, and skin diseases [27].

Concerning information and awareness of people about the health risks of the sand fly, we asked our participants: "Have you ever been informed about diseases transmitted by a sand fly?" And if the answer is yes, then who has been? It turned out that $64.8 \%$ had never been informed before. Among those who answered yes, the Internet was their means of obtaining information (47.5\%), followed by neighbours and friends (45.5\%). This finding was also found in Fernando's study in Colombia on knowledge about CL and its vector, where he found that most people were informed about the disease through their family and colleagues [33].

3.4. Preventive and Protective Measures against the Risks of Sand Fly. Table 5 shows the methods most commonly used by citizens to protect themselves against the risks associated with sand fly infestations. We asked our participants the 
following question: "In your opinion, can sand fly be avoided?" It turned out that more than half (52.7\%) thought that these insects could not be avoided, while $42.7 \%$ said that sand fly bites could be avoided by using basil plants (90.8\%) and mint (15.8\%). However, others indicated the effectiveness of powdered pesticides (55.8\%), vinegar (60\%), and lemon $(45.8 \%)$ and only $20 \%$ of participants indicated respect for environmental health as a means of prevention. However, the scientific methods that are recommended to protect against sand fly bites are completely different from those mentioned by respondents. This is why we have proposed to choose one of the methods that should be used in the prevention, namely, mosquito nets, long clothing, and insecticides. The results obtained reveal that more than half of the participants prefer to use an insecticide in the form of the insecticide pump (69.8\%) and mosquito nets (46.6\%). Although the use of long-lasting pesticide-treated nets was recommended in the fight against cutaneous leishmaniasis by WHO [1], their use was only mentioned by $8.9 \%$.

Thus, the analysis of the results on the role of individuals in the fight against disease-carrying insects shows that $26 \%$ thought that it was the responsibility of the Ministry of Health, $18.5 \%$ thought that it was the role of the Ministry of Agriculture, while only $6.4 \%$ said that it was the individual himself or herself who was responsible for vector control. Indeed, WHO recommendations indicate that sustainable control of the spread of vector-borne diseases requires active community participation and a holistic approach that ensures the integration of all sectors including the Ministry of Health, Ministry of Agriculture, Ministry of Education, and individuals. WHO emphasizes the importance of tailoring prevention and control measures to the context of each region and using simple, cost-effective procedures that improve the quality of people's lives, such as the use of nets, health education, early diagnosis, and immediate treatment $[1,31]$.

\section{Conclusions}

By way of conclusion, the present study has revealed, on the one hand, the gaps in knowledge and the misconceptions of individuals about the disease, the vector, the mode of transmission, and the prevention measures. On the other hand, to reveal the negligent behaviours towards leishmaniasis skin lesions that surround the care-seeking practices for this type of dermatosis. This underlines the importance of implementing health education campaigns to increase awareness of cutaneous leishmaniasis. Health awareness and increasing the level of people's awareness of cutaneous leishmaniasis and its vector can be improved by using the popular concepts obtained to simplify scientific terms and adapt them to the culture of the population. This facilitates the understanding of educational messages on the prevention of cutaneous leishmaniasis by individuals and actively integrates them in the process of controlling leishmaniasis in central Morocco and regions with a similar situation.

\section{Data Availability}

The data used in this study are included within the article.

\section{Conflicts of Interest}

The authors declare that are no conflicts of interest regarding the publication of this paper.

\section{Acknowledgments}

The authors would like to thank all those who voluntarily agreed to participate in our study and to share their valuable time and information on the subject, as well as the nursing students from the Higher Institute of Nursing and Health Techniques of Meknes who greatly supported the field research team.

\section{References}

[1] Organisation Mondiale de la Santé, La Lutte Contre Les Leishmanioses Rapport De La Reunion Du Comtie OMS D'experts De La Lutte Contre Les Leishmanioses, World Health Organization, Geneva, Switzerland, 2011.

[2] Organisation Mondiale de la Santé, Relevé Épidémiologique Hebdomadaire, OMS, Geneva, Switzerland, Available on: ISSN 0049-8114, 2016.

[3] Ministère de la Santé Marocaine, Bulletin D’Épidémiologie et de Santé Publique (Juillet 2018), vol. 56, Ministère de la Santé Marocaine, Rabat, Morocco, 2018, Available on: ISSN: 08518238.

[4] Ministère de la Santé Marocaine, Direction de l'Epidémiologie et de Lutte contre les Maladies. Lutte contre les Leishmanioses. Guide des Activités 2010, Ministère de la Santé Marocaine, Rabat, Morocco, 2010.

[5] S. Boussaa, B. Pesson, and A. Boumezzough, "Faunistic study of the sandflies (Diptera: psychodidae) in an emerging focus of cutaneous leishmaniasis in Al Haouz province, Morocco," Annals of Tropical Medicine \& Parasitology, vol. 103, no. 1, pp. 73-83, 2009.

[6] C. Faraj, E. B. Adlaoui, S. Ouahabi et al., "Distribution and bionomic of sand flies in five ecologically different cutaneous leishmaniasis Foci in Morocco," ISRN Epidemiology, vol. 2013, Article ID 145031, 8 pages, 2013.

[7] E. A. Mohamed Mahmoud, S. Faiza, M. Lemine et al., "Geographical distribution and new situation of Leishmania species after the control of cutaneous leishmaniasis foci in Errachidia province, Morocco, in 2014," BioMed Research International, vol. 2016, Article ID 8642373, 7 pages, 2016.

[8] S. Boussaa, Les leishmanioses au Maroc: Epidémiologie et Stratégie de Lutte, Noor Publishing, Riga, Latvia, 2018, https:// www.morebooks.shop/store/gb/book/les-leishmanioses-aumaroc:-epid\%C3\%A9miologie-et-strat\%C3\%A9gie-de-lutte/ isbn/978-620-2-35872-9.

[9] M. Hakkour, M. M. El Alem, A. Hmamouch et al., "Leishmaniasis in Northern Morocco: predominance of Leishmania infantum compared to Leishmania tropica," BioMed Research International, vol. 2019, Article ID 5327287, 7 pages, 2019.

[10] Ministère de la santé Marocaine, Direction de l'Epidémiologie et de Lutte Contre les Maladies. Lutte contre les leishmanioses. Guide des activités 1997, Ministère de la santé Marocaine, Rabat, Morocco, 1997.

[11] K. Kahime, S. Boussaa, A. L.-E. Idrissi, H. Nhammi, and A. Boumezzough, "Epidemiological study on acute cutaneous leishmaniasis in Morocco," Journal of Acute Disease, vol. 5, no. 1, pp. 41-45, 2016. 
[12] K. El-Mouhdi, A. Chahlaoui, A. E.-O. Lalami, J. Bouzid, H. E. Omari, and M. Fekhaoui, "Situation épidémiologique des leishmanioses au niveau de la ville d'El Hajeb (Centre du Maroc) durant la période de 2013 à 2017," European Scientific Journal, vol. 15, no. 3, p. 155, 2019.

[13] F. Z. Talbi, F. El Khayyat, H. El Omari et al., "Cartography and epidemiological study of leishmaniasis disease in Sefrou province (2007-2010), Central North of Morocco," Interdisciplinary Perspectives on Infectious Diseases, vol. 2020, Article ID 1867651, 8 pages, 2020.

[14] K. El-Mouhdi, M. Fekhaoui, F. Elhamdaoui, H. Guessioui, and A. Chahlaoui, "Knowledge and experiences of health professionals in the peripheral management of leishmaniasis in Morocco (ELHajeb)," Journal of Parasitology Research, vol. 2020, Article ID 8819704, 9 pages, 2020.

[15] S. Asch, B. Leake, R. Anderson, and L. Gelberg, "Why do symptomatic patients delay obtaining care for tuberculosis?" American Journal of Respiratory and Critical Care Medicine, vol. 157, no. 4, pp. 1244-1248, 1998.

[16] Moroccan Agency for Sustainable Energy, Etude d'Impact Environnemental et Social de la Centrale Solaire Photovoltaique Noor El Hajeb. Conseil Ingnerie Developement, Moroccan Agency for Sustainable Energy, Rabat, Morocco, 2018, http://www.masen.ma/sites/default/files/documents_ rapport/El\%20Hajeb_FESIA_27_07_2018.

[17] Haut Commissariat au Plan, Population Légale Des Régions, Provinces, Préfectures, Municipalités, Arrondissements Et Communes Du Royaume D’après Les Résultats Du RGPH 2014 (12 Régions), Haut Commissariat au Plan, Casablanca, Morocco, 2014, http://www.hcp.ma/Etudes_r161.html.

[18] AgriMaroc.ma, L'oignon Dans la Province d'El Hajeb, AgriMaroc.ma, Marrakech, Morocco, 2019, https://www. agrimaroc.ma/oignon-el-hajeb/.

[19] K. Lahouiti, A. E. O. Lalami, S. Maniar, and K. Bekhti, "Seasonal fluctuations of phlebotomines sand fly populations (Diptera: psychodidae) in the Moulay Yacoub province, centre Morocco: effect of ecological factors," African Journal of Environmental Science and Technology, vol. 7, no. 11, pp. 1028-1031, 2013.

[20] A. Hmamouch, M. M. El Alem, M. Hakkour et al., "Circulating species of Leishmania at microclimate area of Boulemane Province, Morocco: impact of environmental and human factors," Parasites \& Vectors, vol. 10, no. 1, p. 100, 2017.

[21] H. A. A. Khan, W. Akram, S. A. Shad, M. Razaq, U. NaeemUllah, and K. Zia, "A cross-sectional survey of knowledge, attitude and practices related to house flies among dairy farmers in Punjab, Pakistan," Journal of Ethnobiology and Ethnomedicine, vol. 9, no. 1, p. 18, 2013.

[22] R. B. Frary, "A brief guide to questionnaire development," 1998, http://www.ericae.net/ft/tamu/vpiques3.htm.

[23] F. M. Fabienne, C. José, and F. Françoise, Fondements et Étapes du Processus de Recherche, Chenelière éducation, Montréal, Canada, 2006.

[24] S. Koirala, S. C. Parija, P. Karki, and M. L. Das, "Knowledge, attitudes, and practices about kala-azar and its sandfly vector in rural communities of Nepal," Bulletin of the World Health Organization, vol. 76, no. 5, pp. 485-490, 1998.

[25] B. Sarkari, A. Qasem, and M. R. Shafaf, "Knowledge, attitude, and practices related to cutaneous leishmaniasis in an endemic focus of cutaneous leishmaniasis, Southern Iran," Asian Pacific Journal of Tropical Biomedicine, vol. 4, no. 7, pp. 566-569, 2014.
[26] E. D. Doe, A. Egyir-Yawson, and G. Kwakye-Nuako, "Knowledge, attitude and practices related to cutaneous leishmaniasis in endemic communities in the Volta region of Ghana," International Journal of Healthcare Sciences, vol. 7, no. 1, p. 12, 2019.

[27] A. Akram, H. A. A. Khan, A. Qadir, and A. M. Sabir, "A crosssectional survey of knowledge, attitude and practices related to cutaneous leishmaniasis and sand flies in Punjab, Pakistan," PLoS One, vol. 10, no. 6, Article ID e0130929, 2015.

[28] S. Ramdas, "Cruel disease, cruel medicine: self-treatment of cutaneous leishmaniasis with harmful chemical substances in Suriname," Social Science \& Medicine, vol. 75, no. 6, pp. 1097-1105, 2012.

[29] I. Bennis, L. Belaid, V. D. Brouwere, H. Filali, H. Sahibi, and M. Boelaert, "“The mosquitoes that destroy your face". Social impact of Cutaneous Leishmaniasis in south-eastern Morocco, a qualitative study," PLoS One, vol. 12, no. 12, Article ID e0189906, 2017.

[30] N. Abazid, C. Jones, and C. R. Davies, "Knowledge, attitudes and practices about leishmaniasis among cutaneous leishmaniasis patients in Aleppo, Syrian Arab Republic," Eastern Mediterranean Health Journal, vol. 18, no. 1, pp. 7-14, 2012.

[31] Organization PAH, Elimination of Neglected Diseases and other Poverty-Related Infections, PAHO, Washington, DC, USA, 2009, http://iris.paho.org/xmlui/handle/123456789/ 33933.

[32] A. Dobles-Ulloa and C. Perriard, "Representaciones, actitudes y prácticas respecto a la Leishmaniasis Cutánea en la población del Cantón de Acosta, provincia de San José, Costa Rica: estudio antropológico exploratório," Cadernos de Saúde Pública, vol. 10, no. 2, pp. 181-189, 1994.

[33] S. D. Fernando, H. V. Y. D. Siriwardana, K. A. R. C. W. Guneratne, and L. C. Rajapaksa, "Some sociological aspects of cutaneous leishmaniasis in patients attending a tertiary referral centre in Colombo, Sri Lanka," International Health, vol. 2, no. 1, pp. 69-74, 2010.

[34] M. M. Weigel and R. X. Armijos, "The traditional and conventional medical treatment of cutaneous leishmaniasis in rural Ecuador," Revista Panamericana de Salud Pública, vol. 10, no. 6, pp. 395-404, 2001.

[35] M. M. Emami, M. Yazdi, and P. Guillet, "Efficacy of Olyset long-lasting bednets to control transmission of cutaneous leishmaniasis in Iran," Eastern Mediterranean Health Journal, vol. 15, no. 5, pp. 1075-1083, 2009. 